\title{
- castraber \\ Unusual presentation of acute pancreatitis following high tibial osteotomy
}

\author{
Adam O'Connor, Peter Asaad
}

Department of General Surgery, Royal Albert Edward Infirmary, Wigan, UK

Correspondence to Dr Adam O'Connor, a01112@my.bristol.ac.uk

Accepted 22 January 2019

\section{Check for updates}

(c) BMJ Publishing Group Limited 2019. Re-use permitted under CC BY-NC. No commercial re-use. See rights and permissions. Published by BMJ.

To cite: $O^{\prime}$ Connor $A$,

Asaad P. BMJ Case Rep

2019:12:e227438.

doi:10.1136/bcr-2018-

227438

\section{SUMMARY}

We report a case of a 55-year-old man taxi driver admitted electively for high tibial osteotomy for relief of bilateral medial compartment osteoarthritis. He was obese and an ex-smoker but medical history was otherwise unremarkable. Day 1 postoperatively the patient started to suffer vomiting episodes and the abdomen was distended. C Reactive protein and white cell count were both elevated but other bloods were normal. CT abdomen and pelvis was performed which showed acute interstitial pancreatitis. Glasgow score was calculated as 2 . He was treated aggressively with analgesia, intravenous fluid and intravenous antibiotics. He has made a good recovery following these conservative measures. To our knowledge, this is the first case in the literature reporting pancreatitis as a complication of high tibial osteotomy. This case highlights the importance of close monitoring for abdominal complications even in the setting of elective orthopaedic surgery where it is a rare phenomenon.

\section{BACKGROUND}

High tibial osteotomy attempts to correct osteoarthritis of the knee joint by unloading pathological articular surfaces and correcting any angular deformity of the knee. Despite the popularity of total knee arthroplasty, orthopaedic surgeons still see it as a useful procedure where the disease process is confined to one compartment of the knee. ${ }^{1}$ Known complications have been recorded in terms of cardiovascular, neurological or thromboembolic systems. $^{2}$ We present a case of a 55 -year-old man with risk factors electively admitted for bilateral high tibial osteotomy that developed acute interstitial pancreatitis postoperatively. To our knowledge, this is the first case report demonstrating acute pancreatitis as a complication of high tibial osteotomy. It illustrates the need for close monitoring by the orthopaedic surgeons, prompt initial management and then referral to the general surgical team for ongoing care.

\section{CASE PRESENTATION}

This 55-year-old taxi driver was referred to the orthopaedic clinic by his general practitioner following bilateral knee pain, which was described as a persistently dull ache with occasional shooting pains in both medial compartments of the knee. He was obese with body mass index (BMI) 40.4 and had a history of asthma but otherwise in reasonable health. He was an ex-smoker, having quit 6 years ago. He denied excessive alcohol use. Initial X-rays showed evidence of medial compartment osteoarthritis in both knee joints. The orthopaedic team referred the patient for MRI scan, which showed isolated bilateral medial joint osteoarthritis with significant cyst formation and underlying bone oedema. The patient was keen for operative intervention. Preoperative anaesthetic assessment and blood tests were all deemed appropriate enough to continue with the procedure. He was an offered to undergo high tibial osteotomy and was listed for the procedure on an elective basis.

The patient underwent high tibial osteotomy under general anaesthesia at our dedicated orthopaedic site which passed without incident and there were no intraoperative complications or difficulties. There were observations revealing sinus tachycardia on the night of the operation but all other parameters were normal. On the first postoperative day, the patient began to vomit bilious fluid and reported abdominal pain and distension. $\mathrm{He}$ was tachycardic, hypertensive and slightly hypoxic on room air. On examination his abdomen was distended with tenderness to palpation in the right hypochondrium and epigastrium.

\section{INVESTIGATIONS}

Blood tests taken at the orthopaedic hospital following this deterioration revealed haemoglobin of $124 \mathrm{~g} / \mathrm{L}$ CRP of $305 \mathrm{U} / \mathrm{L}$, normal urea and electrolytes, normal clotting screen, normal bone profile, white cell count of $24 \times 10^{9} / \mathrm{L}$ and amylase of $166 \mathrm{U} / \mathrm{L}$. Liver function tests were unremarkable with bilirubin of $13 \mathrm{umol} / \mathrm{L}$ alongside alkaline phosphatase of $111 \mathrm{U} / \mathrm{L}$ and alanine aminotransferase of $38 \mathrm{U} / \mathrm{L}$. Arterial blood gas revealed mild type 1 respiratory failure with a $\mathrm{pH} 7.427$ and $\mathrm{PaO} 2$ of $8.99 \mathrm{kPa}$. Lactate was not raised. Rapid fluid resuscitation was commenced alongside antibiotics.

Given the acute deterioration of the patient he was transferred to our local acute site where CT abdomen and pelvis was organised on his first postoperative day (figure 1). This clinical deterioration occurred at weekend where abdominal ultrasound is not available and given his acute abdomen, CT scan was felt to be the more appropriate investigation. This CT scan demonstrated acute interstitial pancreatitis with inflammatory changes of the anterior pararenal space alongside acute fluid collections in the lesser sac and pelvic retroperitoneal space (figure 2). Pancreatic necrosis was not present. Inflammatory ileus was demonstrated. There was no evidence of pneumoperitoneum or 


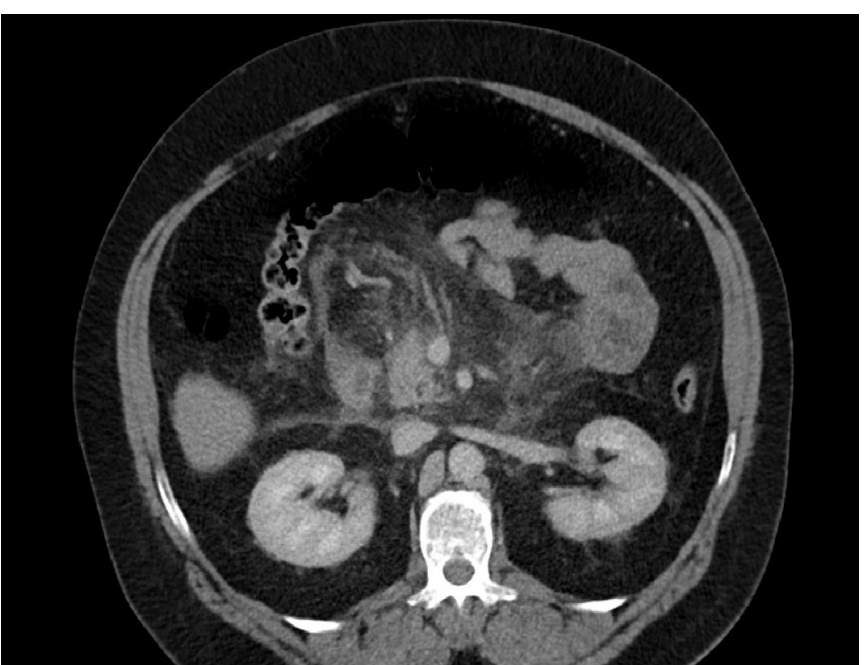

Figure 1 CT scan of the abdomen demonstrating acute interstitial pancreatitis.

bowel obstruction. No biliary pathology was identified on the CT scan.

\section{DIFFERENTIAL DIAGNOSIS}

Differential diagnoses at this time included pancreatitis, bowel obstruction, perforation or biliary tree pathology. However, given the normal LFTs suspicion of gallstones as the aetiology of the pancreatitis seemed unlikely. Clear radiological evidence of pancreatitis on CT scan made this the primary diagnosis.

\section{TREATMENT}

Intravenous fluids were continued at a rapid rate, the patient catheterised and analgesia continued through fentanyl patient controlled analgesia. Urinary output was adequate and there were no concerns regarding fluid balance. The patient continued to be hypertensive and tachycardic due to pain and required doses of both amlodipine and doxazosin to return this to normal parameters. Medical opinion was sought and regular amlodipine commenced. Arterial blood gases showed a mild type 1 respiratory failure with $\mathrm{PaO} 2$ of 8.99 but the overall Glasgow pancreatitis score was 2 . Following these measures there was obvious

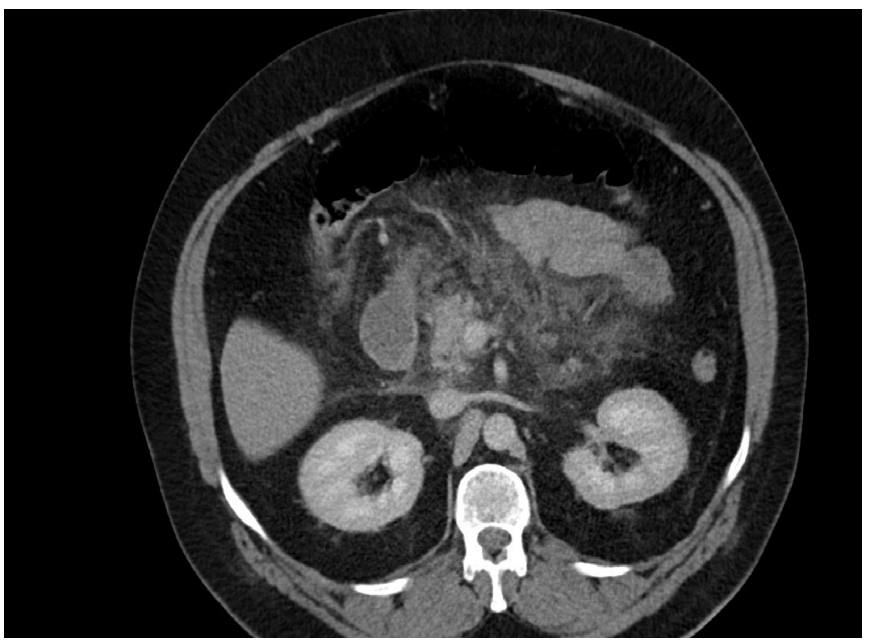

Figure 2 CT scan demonstrating pancreatitis in addition to fluid collections in the retroperitoneal space and transverse mesocolon. clinical improvement in terms of pain, abdominal distension and clinical observations. We sought opinion from the intensivists who felt that there was no indication for intensive care unit admission given the patient's clinical improvement to our interventions. The local hepatobiliary regional centre was also consulted for their opinion who advised for repeat CT scan in 1 weeks' time if there was no clinical improvement.

\section{OUTCOME AND FOLLOW-UP}

Throughout the patient's admission under general surgery, he was reviewed daily by the orthopaedic team. They were happy with the knee wound postoperatively and had little further to add from an orthopaedic perspective.

Ultimately, following aggressive fluid replacement, appropriate analgesia and antihypertensive therapy, the patient's clinical condition improved and there was no indication for repeat CT. From an orthopaedic perspective, the patient will be followed up in clinic in the coming months to ensure adequate mobility following his operation.

\section{DISCUSSION}

Despite total knee arthroplasty still being the mainstay for operative relief of symptomatic osteoarthritis, high tibial osteotomy is favoured by orthopaedic surgeons when there is presence of unicompartmental disease. ${ }^{1}$ There are well documented complications of the procedure in terms of cardiac, thromboembolic or neurological issues but gastrointestinal complications, particularly the presence of pancreatitis are extremely rare. ${ }^{2}$ When gastrointestinal complications do occur they tend to be related to gastrointestinal bleeding, gastritis and ileus. ${ }^{3}$ Indeed we can find no evidence in English medical literature of a case report describing acute pancreatitis as a complication following high tibial osteotomy. There appears to be a Singaporean case report outlining pancreatitis in a patient following bilateral total knee arthroplasty. ${ }^{4}$ This is a much more complex and longer procedure with a longer operating time and is a different procedure altogether to high tibial osteotomy. However it does pose the question as to whether pancreatitis postoperatively is a more common complication than perhaps given credit for in the orthopaedic setting.

Acute pancreatitis is a common condition that varies in terms of its severity from mild to life threatening. If it is recognised and dealt with rapidly, this has a profound impact on outcomes. ${ }^{5}$ Common symptoms include nausea, vomiting and abdominal pain with radiation into the back. Signs may be present in the form of persistent tachycardia and hypotension in a 'systemical inflammatory response syndrome' picture. ${ }^{6}$ In the acute setting, $80 \%$ of pancreatitis is due to gallstones and excessive alcohol consumption. Despite being a rare consequence of orthopaedic surgery, pancreatitis is a well-established complication of abdominal procedures as well as being reported in vascular, cardiothoracic and endocrine surgery. ${ }^{78}$ Therefore in all patients with abdominal pain irregardless of the operation, acute pancreatitis should be considered as a differential diagnosis.

In this case, our patient did not have many of the recognised risk factors for pancreatitis. However he was obese with a BMI of 40 and there is an increasing weight of evidence associating obesity with increased risk of pancreatitis, and in particular severe pancreatitis. A systematic review by Premkumar et al found that obesity is associated with an increased inflammatory response in the setting of acute pancreatitis and furthermore was a useful prognostic indicator for mortality, systemic and local complications as well as severity of acute pancreatitis. They did not however find 
a connection between obesity and multiorgan failure in obese patients who develop acute pancreatitis. ${ }^{9}$ Navina et al used severe pancreatitis as a disease to assess if obesity affected organ function. They found that a larger number of pancreatic adipose tissue contributed to more severe pancreatic necrosis during acute pancreatitis. Biochemically this was due to proinflammatory processes from unsaturated fatty acids. ${ }^{10}$ Additionally, we cannot find any lipid levels being taken preoperatively on this patient and hypercholesterolaemia may also have played a part given the patient's obesity. Postoperatively, he did present with classic features of pancreatitis and these were acted on swiftly.

To summarise, we present a case of a patient with acute interstitial pancreatitis following elective high tibial osteotomy. Should a postoperative orthopaedic patient with risk factors develop sudden abdominal pain, distension, persistent tachycardia and raised inflammatory markers, general surgical opinion should be sought as a matter of urgency. The complication of pancreatitis and the acute abdomen postelective orthopaedic surgery is a highly rare but highly important one that should be acted on quickly in order to improve outcome.

Learning points

- Abdominal complications are a rare entity of orthopaedic surgery, as well as complicating recovery in abdominal, vascular and endocrine surgery.

- Swift recognition and diagnosis improve outcomes.

- Rapid intravenous fluids and analgesia early prior to CT scan improves outcomes.

- Despite being rare in the orthopaedic setting, the acute abdomen should be considered in postoperative orthopaedic patients with ongoing tachycardia.
Contributors AO drafted the manuscript, made amendments to subsequent versions, gained patient consent and edited the images.PA aided with editing subsequent versions of the manuscript as well as suggesting the possibility of writing up this case.

Funding The authors have not declared a specific grant for this research from any funding agency in the public, commercial or not-for-profit sectors.

Competing interests None declared.

Patient consent Obtained.

Provenance and peer review Not commissioned; externally peer reviewed.

Open access This is an open access article distributed in accordance with the Creative Commons Attribution Non Commercial (CC BY-NC 4.0) license, which permits others to distribute, remix, adapt, build upon this work non-commercially, and license their derivative works on different terms, provided the original work is properly cited and the use is non-commercial. See: http://creativecommons.org/ licenses/by-nc/4.0/

\section{REFERENCES}

1 Wright JM, Crockett HC, Slawski DP, et al. High tibial osteotomy. J Am Acad Orthop Surg 2005;13:279-89.

2 Restrepo C, Parvizi J, Dietrich T, et al. Safety of simultaneous bilateral total knee arthroplasty. A meta-analysis. J Bone Joint Surg Am 2007:89:1220-6.

3 Ritter MA, Harty LD. Debate: simultaneous bilateral knee replacements: the outcomes justify its use. Clin Orthop Relat Res 2004;428:84-6.

4 Seah RB, Chia SL, Puah KL, et al. An atypical presentation of acute pancreatitis after simultaneous bilateral total knee replacement: A case report. J Orthop 2013;10:200-3.

5 Wu BU, Conwell DL. Update in acute pancreatitis. Curr Gastroenterol Rep 2010;12:83-90.

6 Spanier BW, Dijkgraaf MG, Bruno MJ. Epidemiology, aetiology and outcome of acute and chronic pancreatitis: an update. Best Pract Res Clin Gastroenterol 2008;22:45-63.

7 Burkey SH, Valentine RJ, Jackson MR, et al. Acute pancreatitis after abdominal vascular surgery. J Am Coll Surg 2000;191:373-80.

8 Reeve TS, Delbridge LW. Pancreatitis following parathyroid surgery. Ann Surg 1982;195:158-62.

9 Premkumar R, Phillips AR, Petrov MS, et al. The clinical relevance of obesity in acute pancreatitis: targeted systematic reviews. Pancreatology 2015;15:25-33.

10 Navina S, Acharya C, DeLany JP, et al. Lipotoxicity causes multisystem organ failure and exacerbates acute pancreatitis in obesity. Sci Trans/ Med 2011;3:107ra110.

Copyright 2019 BMJ Publishing Group. All rights reserved. For permission to reuse any of this content visit

https://www.bmj.com/company/products-services/rights-and-licensing/permissions/

BMJ Case Report Fellows may re-use this article for personal use and teaching without any further permission.

Become a Fellow of BMJ Case Reports today and you can:

- Submit as many cases as you like

- Enjoy fast sympathetic peer review and rapid publication of accepted articles

- Access all the published articles

- Re-use any of the published material for personal use and teaching without further permission

For information on Institutional Fellowships contact consortiasales@bmjgroup.com

Visit casereports.bmj.com for more articles like this and to become a Fellow 